This article was downloaded by: [Archives \& Bibliothèques de I'ULB]

On: 16 March 2015, At: 03:20

Publisher: Routledge

Informa Ltd Registered in England and Wales Registered Number: 1072954 Registered

office: Mortimer House, 37-41 Mortimer Street, London W1T 3J H, UK

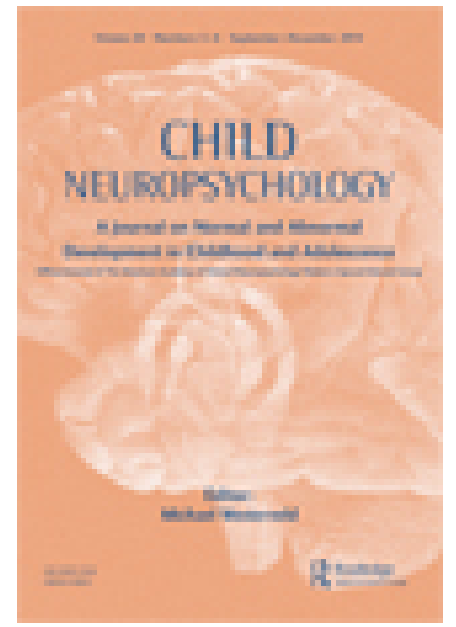

CrossMark

Click for updates

\section{Child Neuropsychology: A J ournal on Normal and Abnormal Development in Childhood and Adolescence}

Publication details, including instructions for authors and subscription information:

http:// www.tandfonline.com/ loi/ ncny20

\section{Executive and attentional contributions to Theory of Mind deficit in attention deficit/hyperactivity disorder (ADHD)}

Alison Mary $^{\text {ad }}$, Hichem Slama ${ }^{\text {acde }}$, Philippe Mousty ${ }^{\text {bd }}$, Isabelle Massat $^{\text {adfg }}$, Tatiana Capiau ${ }^{\text {bd }}$, Virginie Drabs $^{\text {bd }} \&$ Philippe Peigneux ${ }^{\text {ad }}$

a Neuropsychology and Functional Neuroimaging Research Unit, Center for Research in Cognition and Neurosciences, Université Libre de Bruxelles, Brussels, Belgium

${ }^{b}$ Cognition Language Development Laboratory, Center for Research in Cognition and Neurosciences, Université Libre de Bruxelles, Brussels, Belgium

${ }^{c}$ Cognitive Neurosciences Research Unit, Center for Research in Cognition and Neurosciences, Université Libre de Bruxelles, Brussels, Belgium

d ULB Neuroscience Institute, Université Libre de Bruxelles, Brussels, Belgium

e Department of Clinical and Cognitive Neuropsychology, Erasme Hospital, Université Libre de Bruxelles, Brussels, Belgium

f Laboratory of Experimental Neurology, Université Libre de Bruxelles, Brussels, Belgium

${ }^{9}$ Department of Neurology, Erasme Hospital, Université Libre de Bruxelles, Brussels, Belgium

Published online: 12 Mar 2015.

To cite this article: Alison Mary, Hichem Slama, Philippe Mousty, Isabelle Massat, Tatiana Capiau, Virginie Drabs \& Philippe Peigneux (2015): Executive and attentional contributions to Theory of Mind deficit in attention deficit/ hyperactivity disorder (ADHD), Child Neuropsychology:

A J ournal on Normal and Abnormal Development in Childhood and Adolescence, DOI:

10.1080/09297049.2015.1012491

To link to this article: http:// dx. doi. org/ 10.1080/09297049.2015.1012491 
Taylor \& Francis makes every effort to ensure the accuracy of all the information (the "Content") contained in the publications on our platform. However, Taylor \& Francis, our agents, and our licensors make no representations or warranties whatsoever as to the accuracy, completeness, or suitability for any purpose of the Content. Any opinions and views expressed in this publication are the opinions and views of the authors, and are not the views of or endorsed by Taylor \& Francis. The accuracy of the Content should not be relied upon and should be independently verified with primary sources of information. Taylor and Francis shall not be liable for any losses, actions, claims, proceedings, demands, costs, expenses, damages, and other liabilities whatsoever or howsoever caused arising directly or indirectly in connection with, in relation to or arising out of the use of the Content.

This article may be used for research, teaching, and private study purposes. Any substantial or systematic reproduction, redistribution, reselling, loan, sub-licensing, systematic supply, or distribution in any form to anyone is expressly forbidden. Terms \& Conditions of access and use can be found at http://www.tandfonline.com/page/termsand-conditions 


\title{
Executive and attentional contributions to Theory of Mind deficit in attention deficit/hyperactivity disorder (ADHD)
}

\author{
Alison Mary ${ }^{1,4}$, Hichem Slama ${ }^{1,3,4,5}$, Philippe Mousty ${ }^{2,4}$, \\ Isabelle Massat ${ }^{1,4,6,7}$, Tatiana Capiau ${ }^{2,4}$, Virginie Drabs ${ }^{2,4}$, and \\ Philippe Peigneux ${ }^{1,4}$
}

${ }^{1}$ Neuropsychology and Functional Neuroimaging Research Unit, Center for Research in Cognition and Neurosciences, Université Libre de Bruxelles, Brussels, Belgium

${ }^{2}$ Cognition Language Development Laboratory, Center for Research in Cognition and Neurosciences, Université Libre de Bruxelles, Brussels, Belgium

${ }^{3}$ Cognitive Neurosciences Research Unit, Center for Research in Cognition and Neurosciences, Université Libre de Bruxelles, Brussels, Belgium

${ }^{4}$ ULB Neuroscience Institute, Université Libre de Bruxelles, Brussels, Belgium

${ }^{5}$ Department of Clinical and Cognitive Neuropsychology, Erasme Hospital, Université Libre de Bruxelles, Brussels, Belgium

${ }^{6}$ Laboratory of Experimental Neurology, Université Libre de Bruxelles, Brussels, Belgium ${ }^{7}$ Department of Neurology, Erasme Hospital, Université Libre de Bruxelles, Brussels, Belgium

Attention deficit/hyperactivity disorder (ADHD) in children has been associated with attentional and executive problems, but also with socioemotional difficulties possibly associated with deficits in Theory of Mind (ToM). Socioemotional problems in ADHD are associated with more negative prognoses, notably interpersonal, educational problems, and an increased risk of developing other psychiatric disorders that emphasize the need to clarify the nature of their ToM deficits. In this study, we hypothesized that ToM dysfunction in children with ADHD is largely attributable to their attentional and/or executive deficits. Thirty-one children with ADHD (8-12 years, IQ > 85) and 31 typically developing (TD) children were assessed using executive functions (inhibition, planning, and flexibility) and attentional tasks, as well as two advanced ToM tasks (Reading the Mind in the Eyes and Faux Pas) involving different levels of executive control. Children with ADHD performed more poorly than TD children in attentional, executive function, and ToM tasks. Linear regression analyses conducted in the ADHD group indicated that inhibition scores predicted performance on the "Faux Pas" task the best, while attention scores were the best for predicting performance on the Reading the Mind in the Eyes task. When controlled for inhibition and attentional variables, ToM performance in

We warmly thank the children and their parents who kindly took part in this research, as well as the schools and the teachers who agreed to collaborate in this study. The authors declare that the research was conducted in the absence of any commercial or financial relationships that could be construed as a potential conflict of interest. The authors also thank Jeromy Hrabovecky for proofreading and language editing in this article.

No potential conflict of interest was reported by the author(s).

This research was partially supported by the Belgian National Fund for Scientific Research [Grant number FNRS 3.4.516.08 .F]. AM, IM and VD are supported by the Belgian National Fund for Scientific Research (FNRS).

Address correspondence to Hichem Slama, Neuropsychology and Functional Neuroimaging Research Unit, Université Libre de Bruxelles, CP191, Avenue F. D. Roosevelt 50, 1050 Brussels, Belgium. E-mail: hichem.slama@ulb.ac.be

Alison Mary and Hichem Slama are equal contributors for this work. 
children with ADHD was actually similar to TD children. Contrarily, controlling for ToM scores did not normalize performance for inhibition and attentional tasks in children with ADHD. This unidirectional relationship suggests that deficits in the EF and attentional domains are responsible for ToM deficits in ADHD, which therefore may contribute to their socioemotional difficulties.

Keywords: ADHD; Cognition; Attention; Theory of Mind; Executive functions.

Attention deficit/hyperactivity disorder (ADHD) is a common neurodevelopmental disorder occurring in 3-5\% of children (American Psychiatric Association, 2000). Although the diagnosis is established on a behavioral basis, cognitive deficits can be observed especially in the domain of executive functions (e.g., Barkley, 1998; Sergeant, Geurts, \& Oosterlaan, 2002; Willcutt, Doyle, Nigg, Faraone, \& Pennington, 2005) and attentional processes (e.g., Drechsler, Brandeis, Foldenyi, Imhof, \& Steinhausen, 2005; Pasini, Paloscia, Alessandrelli, Porfirio, \& Curatolo, 2007; Tucha et al., 2006). Executive functions (EF) refer to top-down cognitive processes that are required when relying on automatic behaviors is insufficient. Previous research has evidenced at least three core cognitive processes in EF, namely inhibition (controlled suppression of automatic responses and distractors), working memory (short-term storage and active manipulation of information), and flexibility (adaptation to changed demands) (Diamond, 2013; Miyake, Friedman, Emerson, Witzki, \& Howerter, 2000). These EF promote the development of higher order EF, such as reasoning, problem solving, and planning (Diamond, 2013).

Along with EF deficits, socioemotional impairments are frequently reported in ADHD (e.g., Fahie \& Symons, 2003; Nijmeijer et al., 2008; Uekermann et al., 2010). ADHD can result in inappropriate social behavior, which may arise from a poorer social repertoire and a failure to understand the impact of their actions on others (Nijmeijer et al., 2008). These socioemotional difficulties may have long-term repercussions on the futures of children with ADHD in that poor social relationships are strong predictors and mediators of negative adult outcomes (Daly, Creed, Xanthopoulos, \& Brown, 2007). In the current study, we investigated Theory of Mind (ToM) in ADHD, as it represents a particular and complex aspect of social cognition that relies on the ability to attribute mental states (desires, beliefs, feelings, thoughts, and intentions) to oneself and others and to predict and understand people's behavior based on their mental states (Premack \& Woodruff, 1978). ToM progressively emerges during child development, starting with the ability to understand others' beliefs about a situation (first-order ToM), followed by with the understanding that people have specific beliefs about the beliefs and thoughts of other people (second-order ToM) and finally with the development of higher order ToM competences ("advanced" ToM) involving more complex social situations.

Investigations of ToM features in patients with ADHD have produced inconsistent findings. Furthermore, despite well-recognized social difficulties in this population, studies still remain surprisingly scarce (for a brief review, see Slama, Mary, Mousty, Massat, \& Peigneux, 2011). Contradicting the hypothesis of a deficit in ToM functions in ADHD, several studies have found similar performances in various ToM tasks in children with ADHD in comparison with typically developing children (Charman, Carroll, \& Sturge, 2001; Perner, Kain, \& Barchfeld, 2002; Yang, Zhou, Yao, Su, \& McWhinnie, 2009) and better performance when compared to children with autism spectrum disorder (ASD; Yang et al., 2009). Despite this absence of ToM dysfunction, most of these studies highlighted executive deficits in children with ADHD. These findings suggest that executive problems do not necessarily lead to ToM deficits in ADHD. Charman et al. 
found that children with ADHD had lower social competencies as assessed by parental questionnaires and made more errors in an executive inhibition task, yet performed at the same level as typically developing children in an executive planning task and in an advanced ToM paradigm. Likewise, Perner et al. found deficits in attentional and planning tasks in preschoolers at risk for $\mathrm{ADHD}$, but not in other EF (inhibition, flexibility, and working memory) nor in ToM second-order tasks. Finally, Yang et al. found similar performance in both EF and ToM tasks in children with ADHD as in typically developing children, whereas they observed ToM deficits with intact EF in a third group of children with ASD, suggesting that EF and ToM are dissociable to some extent. However, Yang et al. only used first-order ToM tasks to evaluate ToM in children aged between 3 and 15 years old. First-order task may have been appropriate for the younger children, but the older children may have exhibited a ceiling effect on this measure. Significant correlations between performance in inhibition and higher order ToM tasks were found in some of these studies, which support the proposal that an inhibition component intervenes in ToM (Charman et al., 2001; Perner et al., 2002).

Conversely, other studies have identified both ToM and EF alterations in children suffering from attentional deficits (Papadopoulos, Panayiotou, Spanoudis, \& Natsopoulos, 2005), in so-called "hard-to-manage" preschoolers exhibiting hyperactivity (Hughes, Dunn, \& White, 1998) and in children with ADHD (Buitelaar, Van Der Wees, Swaab-Barneveld, \& Van Der Gaag, 1999; Sodian, Hülsken, \& Thoermer, 2003). Hughes et al. evidenced inhibitory and ToM deficits in "hard-to-manage" children with hyperactivity compared to typically developing children. Papadopoulos et al. (2005) showed that children with an attention deficit were significantly impaired in second-order ToM and planning tasks but not in first-order ToM and flexibility tasks, as compared to typically developing children. Buitelaar et al. proposed that the high inhibition and working memory abilities required in ToM tasks are responsible for poor performance in second-order false beliefs in children with ADHD. In line with this proposal, children with ADHD performed worse than typically developing children in advanced ToM tasks that require a high level of inhibition (Sodian et al., 2003). These studies suggest that metacognitive impairments in children with ADHD could be explained by executive dysfunctions, which may eventually lead to a tendency to neglect mental states in social situations. In line with this assumption, Bühler, Bachmann, Goyert, Heinzel-Gutenbrunner, and Kamp-Becker (2011) proposed that, contrary to children with ASD, there is no genuine ToM deficit in ADHD since children with ADHD do not exhibit a ToM deficit at an early age. It is surmised that social problems in ADHD might develop when they become older ( $>10$ years) as the EF demands during social situations become higher (Bühler et al., 2011).

The lack of consistency between the aforementioned findings might be related to methodological differences or weaknesses in some studies (e.g., wide age range, type of cognitive tasks used, more or less defined clinical populations and ADHD diagnosis criteria). First, only three studies had included attentional measures (Fahie \& Symons, 2003; Papadopoulos et al., 2005; Perner et al., 2002), whereas this ability is known to be impaired in ADHD. Inattentive symptoms may prevent the child from paying attention to relevant social cues, therefore precluding a correct interpretation of the social situation, which is a necessary step in selecting an adapted behavior. Second, the ADHD diagnosis clearly is not well defined in some studies, as it is sometimes based only on questionnaires (Hughes et al., 1998; Papadopoulos et al., 2005; Perner et al., 2002), and the presence of comorbid disorders is not always controlled (Fahie \& Symons, 2003; Hughes et al., 1998). Comorbidities, such as oppositional defiant disorder, pervasive development disorder, or conduct disorder, can be considered additional risk factors for social dysfunction in 
ADHD (Nijmeijer et al., 2008). Third, EF as well as ToM are multidimensional constructs. Therefore, the lack of difficulties in one specific ToM or EF task does not mean that children with ADHD will perform at the same level as typically developing children in all other ToM or EF tasks. Differences between studies may also lie in the choice of tasks used to assess ToM functions. Some ToM tasks (first-order false belief tasks and the advanced Happe Strange Stories task) are suggested to be less sensitive for identifying ToM deficits in patients with acquired neurological pathologies and to be actually linked less to EF (Aboulafia-Brakha, Christe, Martory, \& Annoni, 2011). Likewise, first-order false belief tasks (Buitelaar et al., 1999; Hughes et al., 1998; Papadopoulos et al., 2005; Yang et al., 2009) and the Happe Strange Stories task (Charman et al., 2001) have failed at engendering performance differences between typically developing children and children with ADHD, thus showing their lack of sensitivity. Finally, the involvement of EF in ToM tasks is variable and should therefore be controlled when evaluating ToM processes in populations known to have EF difficulties (e.g., ADHD or ASD).

To sum up, EF deficits in children with ADHD are reported frequently in the literature and have been proposed as a valid endophenotype for ADHD (Durston, de Zeeuw, \& Staal, 2009). However, based on the aforementioned findings, it cannot be concluded with certainty that children with ADHD exhibit consistent ToM deficits. Beyond the existing correlations between performance in EF and ToM, higher deficits in ADHD for ToM tasks that require a higher level of EF may also support the hypothesis that potential ToM dysfunctions in children with ADHD may be attributed to attentional or executive deficits. Therefore, in the present study we investigate this hypothesis using higher order ToM tasks and a comprehensive assessment of attentional and executive functions. Carefully matched typically developing children and children with ADHD without comorbidities underwent a neuropsychological battery of EF and attentional tasks known to be generally impaired in ADHD. Two advanced ToM tasks were also administered. These two ToM tasks involve abilities that typically develop within the age bracket of the present study (8-12 years). The Reading the Mind in the Eyes task (Baron-Cohen, Wheelwright, Spong, Scahill, \& Lawson, 2001) is an advanced ToM task that is characterized by low executive demands (Stone, Baron-Cohen, Calder, Keane, \& Young, 2003) contrary to the "Faux Pas" task (Baron-Cohen, O'Riordan, Stone, Jones, \& Plaisted, 1999), which puts higher demands on the executive system. The difference in EF involvement between these two tasks will help in assessing the specific impact of EF and attentional deficits on the ability to interpret mental states in children with ADHD.

\section{METHODS}

\section{Participants}

Thirty-one children with ADHD (17 boys) and 31 typically developing children (14 boys) aged 8-12 years participated in this study approved by the local ethical committee. Mean age was 10.34 years $(S D=0.87)$ in children with ADHD and 10.05 years $(S D=0.68)$ in typically developing children (no significant difference between groups), $t(60)=1.42, p=.16$. The children's parents signed an informed consent prior to their children's participation in the study, and children were orally asked permission prior to participation. The children were not compensated for their participation in the study. All children were attending normal primary schools.

Patients were recruited through the outpatient clinic of the department of Pediatric Neurology at the university hospital. A multidisciplinary team (a child psychiatrist or a child 
neurologist, and a neuropsychologist, all with training and experience in the diagnosis of ADHD and its most frequent comorbidities) assigned diagnoses according to the Diagnostic and Statistical Manual for Mental Disorders, text revision (DSM-IV-TR) criteria for ADHD (American Psychiatric Association, 2000). Diagnoses were based on several clinical interviews with parents and patients, on family and personal background, on physical examination, on school and behavioral reports, on questionnaires (e.g., Revised Conners' Parent Rating Scale; Goyette, Conners, \& Ulrich, 1978), and on a cognitive assessment. The parents of the children with ADHD also completed the Disruptive Behavior Rating Scaleparent version (DBRS-PV; Barkley \& Murphy, 1998). These children were rated above the cut-off score for items related to inattentive $(M=16.24$, cut-off scores are 15 for boys and 12 for girls) and hyperactive-impulsive ( $M=15.41$, cut-off scores are 15 for boys and 9 for girls) symptoms, and below the cut-off for oppositional defiant disorder $(M=3.53$, cut-off score $=4)$ and conduct disorder $(M=0.71$, cut-off score $=3)$. Among the ADHD sample, 3 children were diagnosed with a predominantly inattentive subtype and 28 children with a combined subtype. Children with ADHD on stimulant medication $(n=14)$ suspended their treatment at least 24 hours before testing. Typically developing children were recruited from primary schools in Brussels. The parents of the typically developing children rated ADHD symptoms using the Revised Conners' Parent Rating Scale (Goyette et al., 1978) in order to exclude children presenting ADHD symptoms from the comparison group (total score $>1.5$ ). No child was excluded according to this criterion. Exclusion criteria in both groups were the presence of pervasive developmental disorders (e.g., autism), epilepsy, severe neurological pathology, fetal alcoholism syndrome, Tourette syndrome, psychosis, or an estimated IQ score $<85$. Estimated IQ was computed based on two Perceptual processing (Picture concepts, Matrix reasoning) and two Verbal comprehension (Similarities, Comprehension) subtests of the Wechsler Intelligence Scale for children (WISC-IV: Wechsler, 2005). Intellectual assessment aimed to exclude children with an intellectual weakness. No child was excluded according to this criterion. IQ was not used to match ADHD and typically developing children because it is influenced by attentional and executive factors (Alloway, 2010; Arffa, 2007; Barbey et al., 2012; Friedman et al., 2006; Schweizer, Moosbrugger, \& Goldhammer, 2005). Typically developing children (estimated IQ $=113 \pm 7.73$ ) performed higher than children with ADHD (estimated IQ $=102 \pm 8.91$ ) on IQ measures, $t$ $(60)=-5.13, p<.001$.

\section{Materials}

Attentional and Executive Functions. The computerized Test for Attentional Performance (TAP; Zimmermann \& Fimm, 2004) battery and adapted neuropsychological tasks were used to assess different components of attention and EF.

Attentional abilities were assessed using the Alertness and Divided Attention subtests of the TAP. Alertness is defined as achieving and maintaining a state of high sensitivity to incoming stimuli (Posner, 2008). It refers to general wakefulness and measures the ability to quickly detect stimuli appearing at varying intervals. The alertness subtest was examined under two conditions: a simple reaction time task (tonic alertness) in which a cross appeared on the screen at random intervals and the children had to respond as fast as possible by pressing a key; and an auditory-cued reaction time task (phasic alertness) in which a warning tone preceded the apparition of the cross. In the divided attention subtest, the children had to process simultaneously visual and auditory 
stimuli. The children had to respond as fast as possible by pressing a key when four crosses were forming a square and when they heard two identical tones consecutively.

Inhibition was evaluated using a Counting Stroop task (Bush et al., 1998, 1999) and the Go/No-Go subtest of the computerized TAP battery (Zimmermann \& Fimm, 2004). The Counting Stroop task was adapted in the laboratory and included three conditions: counting, reading, and interference. Items were presented on a computer screen on 10 lines presented one at time with 10 stimuli per line (squares with number or dot). In the counting condition, the children had to report the number of dots within each square as fast as possible. In the reading condition, they had to read the number written within each square. In the interference condition, they had to report how many numbers were written within each square, while having to avoid reading the number itself. The dependent measures for each condition were total response time and number of errors.

Cognitive flexibility (also called task switching) was assessed using the Flexibility subtest of the TAP battery (Zimmermann \& Fimm, 2004) and an adapted version of the Revised Wisconsin Card Sorting Test (RCST; Nelson, 1976). In the Flexibility subtest of the TAP, one angular figure and one round figure appear side-by-side on the screen and switch positions randomly across trials. Participants were told to alternate their focus between each of the figures - first the angular figure, then the round figure, then the angular figure, and so on - and then to indicate which side of the screen the target figure appeared on by pressing either a left or right key on a button box. In our version of the RCST, the children had to classify a set of 48 cards according to three possible dimensions (color, shape, or number). There was only one correct dimension or rule during each trial, which the child had to discover based on the experimenter's feedback. Happy and sad character pictures were used to inform the children whether the chosen rule was correct or incorrect.

The children were also administered a child-adapted version of the Tower of London (Shallice, 1982) to assess planning. This version comprised fewer trials than the adult version (seven total trials including five neutral trials varying from three to seven moves, one negative and one positive trial each with five moves) and was not computerized.

Theory of Mind. Aside from soliciting ToM abilities, success in the "Faux Pas" task additionally requires working memory contribution to maintain essential information from each story and inhibition to refrain from impulsive answers. Conversely, the Reading the Mind in the Eyes test is considered by some authors as a "pure" ToM task (Kaland et al., 2002) devoid of attentional or executive demands. Indeed, in a recent study conducted on typically developing adults, EF variables did not explain a significant proportion of variance in the Reading the Mind in the Eyes performance (Ahmed \& Miller, 2011), suggesting a low executive involvement.

"Faux Pas" Task. The "Faux Pas" task (Baron-Cohen et al., 1999) assesses children's ability (7-11 years) to recognize a "Faux pas" situation, which occurs when a person emits an inappropriate remark, unintentionally, but nevertheless understood as hurtful, embarrassing, or insulting by others. The testing consisted of 10 faux pas and 10 matched control stories. The order of presentation of the 20 stories was randomized among participants. Stories were shown on a computer screen and verbally told using either a male or a female voice, which alternated between stories in order to reinforce children's attention. A control and three ToM questions were asked immediately after each story. The text remained visible during questions to minimize working memory load. The 
control comprehension question aimed at ensuring that children had a correct understanding and were attentive to the story. The first ToM question was the "faux pas" detection question, aimed at determining whether the faux pas situation was detected (e.g., "In the story, did someone say something that she/he should not have said?"). The second ToM question was the "faux pas" identification question, testing whether the sentence in which the faux pas was made was correctly identified (e.g. "What did she/he say that she/ he should not have said?"). Finally, the third ToM question was the false belief question, probing whether it was understood that the faux pas was a consequence of ignorance rather than a deliberate intention to hurt (e.g., "Did she/he know/remember that ...?"). For each story, one point could be earned for each question (maximum four points per story).

Reading the Mind in the Eyes Test. In the children's version of the Reading the Mind in the Eyes test (Baron-Cohen et al., 2001), participants have to infer the mental state of a person from pictures of the eyes only. For each picture, the children had to select a word out of four, which best described the way the person felt. First, four words describing various feelings appeared on the computer screen. Children were then asked for the meaning of each word, and a simple definition was provided in case of failure. After this comprehension phase, 24 pictures of eyes were presented in succession, accompanied by four words. The children were asked to choose the most appropriate word to describe the person's mental state. An English-to-French translation of the material was validated in a sample of 10 young healthy adults. Each correct response earned one point, for a maximal score of 24 .

\section{RESULTS}

Mean differences between the ADHD and control groups were tested using one-way analyses of variance (ANOVAs) and repeated-measures ANOVAs when appropriate. Mauchley's sphericity test was used to verify the sphericity assumption in repeatedmeasures designs, and Greenhouse-Geisser corrected $p$-values were used when necessary. Statistical significance was set at $p=.05$. Effect sizes were computed using partial eta squared $\left(\eta_{p}^{2}\right)$ for repeated-measures ANOVAs and for one-way ANOVAs.

\section{Attentional and Executive Functions (EF) Tasks}

Table 1 shows mean performance values and standard deviations for all tasks. In the TAP subtests, we used the average median as the measure of reaction times (RT) for each group. The subject's median RT was chosen as a measure of response latencies because it is less sensitive than the mean to the enhanced intraindividual variability in the response time usually observed in the ADHD population (Drechsler et al., 2005; Zimmermann \& Fimm, 2004). This latter component was estimated using the coefficient of variation of RTs (standard deviation of RTs / mean RT) in the alertness subtest.

Alertness and Divided Attention. For the Alertness TAP subtest, we used the tonic condition (median RTs and coefficient of variation) and the index of phasic alertness for comparisons between groups. The tonic condition represents a good measure of intrinsic alertness and the index of phasic alertness is used to evaluate the effect of a warning cue on the attentional performance. These analyses revealed slower average 
Table 1 Means $(M)$ and Standard Deviations $(S D)$ for Typically Developing (TD) and ADHD Children in Executive and Attentional Tasks.

\begin{tabular}{|c|c|c|c|c|c|}
\hline & \multicolumn{2}{|c|}{$\mathrm{TD}(n=31)$} & \multicolumn{2}{|c|}{$\operatorname{ADHD}(n=31)$} & \multirow[b]{2}{*}{$p$-value } \\
\hline & $M$ & $S D$ & $M$ & $S D$ & \\
\hline \multicolumn{6}{|l|}{ Tonic-Phasic alertness (TAP) } \\
\hline Tonic alertness mean median (ms) & 283 & 46.48 & 368 & 122.6 & $<0.001$ \\
\hline Tonic alertness mean CV & 0.2 & 0.08 & 0.31 & 0.1 & $<0.001$ \\
\hline Index of phasic alertness & 0.08 & 0.09 & 0.137 & 0.12 & 0.052 \\
\hline \multicolumn{6}{|l|}{ Divided attention } \\
\hline Omissions & 4.13 & 3.23 & 7.84 & 4.24 & $<0.001$ \\
\hline Errors & 2.35 & 4.3 & 5.77 & 11 & 0.11 \\
\hline $\boldsymbol{R} \boldsymbol{C S T}$ (Total errors) & 0.51 & 0.68 & 4.77 & 5.56 & $<0.001$ \\
\hline \multicolumn{6}{|l|}{ Counting Stroop Task } \\
\hline Time interference index (sec) & 33 & 11.84 & 56 & 21.66 & $<0.001$ \\
\hline Errors interference index & 2.16 & 2.15 & 5.13 & 4.87 & 0.003 \\
\hline \multicolumn{6}{|l|}{ Flexibility subtest (TAP) } \\
\hline Mean median (ms) & 863 & 170.44 & 1026 & 249.74 & 0.003 \\
\hline Correct responses $(\%)$ & 94.63 & 6.25 & 87.63 & 9.72 & 0.001 \\
\hline \multicolumn{6}{|l|}{ Go/No-Go (TAP) } \\
\hline Mean median (ms) & 478 & 77.51 & 531 & 104.71 & 0.025 \\
\hline Omissions (\%) & 3.06 & 8.43 & 7.84 & 14.35 & 0.12 \\
\hline Errors $(\%)$ & 15.16 & 16.76 & 21.39 & 16.22 & 0.14 \\
\hline \multicolumn{6}{|l|}{ Tower of London } \\
\hline Sum of exceeding movements & 8.48 & 5.46 & $23.31^{\mathrm{a}}$ & $10.8^{\mathrm{a}}$ & $<0.001$ \\
\hline
\end{tabular}

Note. $\mathrm{CV}=$ Coefficient of variation, $\mathrm{RCST}=$ Revised Card Sorting Test.

${ }^{\mathrm{a}} n=29$.

median reaction times, $F(1,60)=13.03, M S E=8596, p<.001, \eta_{\mathrm{p}}^{2}=.18$, and larger coefficient of variation, $F(1,60)=20.6, M S E=0.086, p<.001, \eta_{\mathrm{p}}^{2}=026$, in ADHD than in the comparison group.

In the Divided Attention TAP subtest, there were more omissions in the ADHD group than in the comparison group, $F(1,60)=15.027, M S E=14.195, p<.001, \eta_{\mathrm{p}}^{2}=.2$.

Inhibition, Flexibility and Planning. In the inhibition (Counting Stroop and Go/No-Go), flexibility (RCST, TAP flexibility), and planning (Tower of London) conditions, children with ADHD had impaired performance as compared to typically developing children (see Table 1).

Two variables were computed to investigate the classical interference effect in the Counting Stroop task, that is, the difference scores were calculated (e.g., MacLeod, 1991) between counting and interference for total time (Time Interference Index) and for the total number of errors (Errors Interference Index). Between-group comparisons revealed significantly larger Time, $F(1,60)=26.98, M S E=304.7, p<.001, \eta_{\mathrm{p}}^{2}=.31$, and Errors Difference scores, $F(1,60)=9.64, M S E=14.16, p=.003, \eta_{p}^{2}=.14$, in ADHD when set against the comparison group. In the Go/No-Go task, mean median RT was larger, $F(1,60)=5.24$, $M S E=8486, p=.025, \eta_{\mathrm{p}}^{2}=.08$, in the ADHD than in the comparison group.

In the Revised Wisconsin Card Sorting Test, the children with ADHD produced more total errors than comparison children, $F(1,60)=17.88, M S E=15.72, p<.001$, 
$\eta_{\mathrm{p}}^{2}=.23$. In the flexibility subtest of the TAP, the average median RT was larger in ADHD $F(1,60)=9.006, M S E=45711, p=.003, \eta_{\mathrm{p}}^{2}=.13$, who also made more errors, $F(1,60)=11.4, M S E=66.8, p=.001, \eta_{\mathrm{p}}^{2}=.16$.

Finally in the Tower of London, the total number of exceeding movements was higher in the ADHD than in the comparison group, $F(1,58)=45.92, M S E=71.72$, $p<.001, \eta_{\mathrm{p}}^{2}=.44$.

\section{ToM Tasks}

"Faux Pas" Task. A repeated-measures ANOVA conducted on the percentage of correct responses in the "faux pas" detection question, with a within-factor Condition ("faux pas" vs. control stories) and a between-factor Group (ADHD vs. typically developing children), revealed a main effect of Condition, $F(1,60)=8.493, M S E=388.9$, $p=.005, \eta_{\mathrm{p}}^{2}=.12$, a trend for the Group effect, $F(1,60)=3.289, M S E=283.4$, $p=.074, \eta_{\mathrm{p}}^{2}=.05$, and a significant Condition by Group interaction effect, $F(1,60)=4.014, M S E=388.9, p<.05, \eta_{\mathrm{p}}^{2}=.06$. Tukey's post hoc tests revealed a lower percentage of correct responses for the "faux pas" question in the "faux pas" condition compared to the control condition in the ADHD group $(p=.005)$ and a lower percentage of correct responses for the "faux pas" question in the "faux pas" condition in ADHD compared to the comparison group ( $p=.02$, see Figure 1).

A repeated-measures ANOVA conducted on the percentage of correct responses in the "Faux pas" stories condition with a within-factor Question Type (mean "faux pas" identification vs. false belief vs. comprehension questions) and a between-factor Group

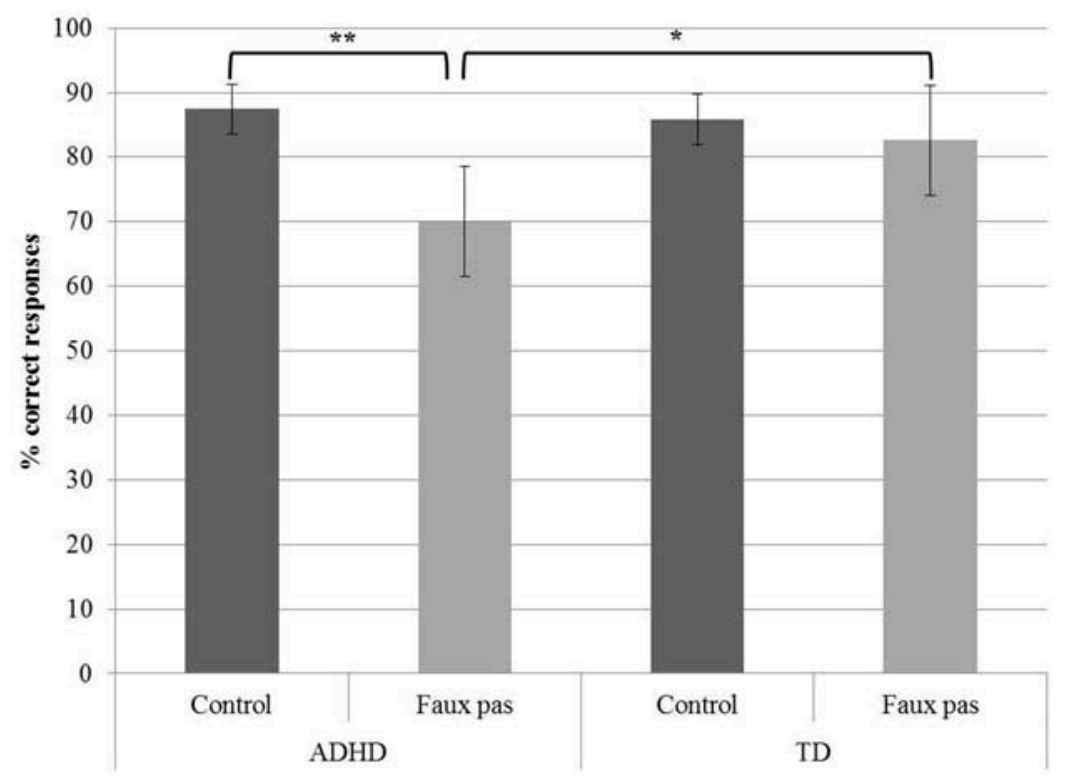

Figure 1 "Faux Pas" task.

Percentage of correct answers and error bars (95\% confidence interval) for the "faux pas" detection question in the Control and "faux pas" stories condition in typically developing (TD) and ADHD children $(* * p<.01, * p<.05)$. 
(ADHD vs. typically developing children) produced main effects of Question Type, $F(2,120)=51.28, M S E=196, p<.001, \eta_{\mathrm{p}}^{2}=.44$, of Group, $F(1,60)=9.06$, $M S E=316, p=.004, \eta_{\mathrm{p}}^{2}=.13$, and a Question Type by Group interaction effect, $F(2,120)=3.42, M S E=196, p=.04, \eta_{\mathrm{p}}^{2}=.05$. Tukey's post hoc tests indicated a lower percentage of correct responses in children with ADHD than in typically developing children for the faux pas identification question $(p=.04$, TD: $80.96 \pm 20.06$; ADHD: $67.42 \pm 26.95)$, but no group differences, for neither the False belief $(p=.31$, TD: $90.97 \pm 9.78$; ADHD: $81.61 \pm 13.69)$ nor for the comprehension $(p=.99$, TD: $100 \pm 0$; ADHD: $99.35 \pm 2.5)$ questions.

Reading the Mind in the Eyes Task and Emotional Abilities. The comparison computed on the percentage of correct responses in the Reading the Mind in the Eyes task (Figure 2) revealed that the children with ADHD performed more poorly than the typically developing children, $F(1,60)=10.18, M S E=227.7, p=.002, \eta_{p}^{2}=.15$.

Relations Between EF and ToM Tasks. Pearson's correlation coefficients were first computed, for the ADHD group, between performance scores obtained from attentional/EF tasks and ToM measures (see Table 2). Executive and attentional tasks scores were selected based on the presence of significant differences between groups (see Table 1). Tasks significantly correlated with ToM were then included in linear regressions as predictors of ToM performance. For ToM tasks, the mean percentage of correct answers

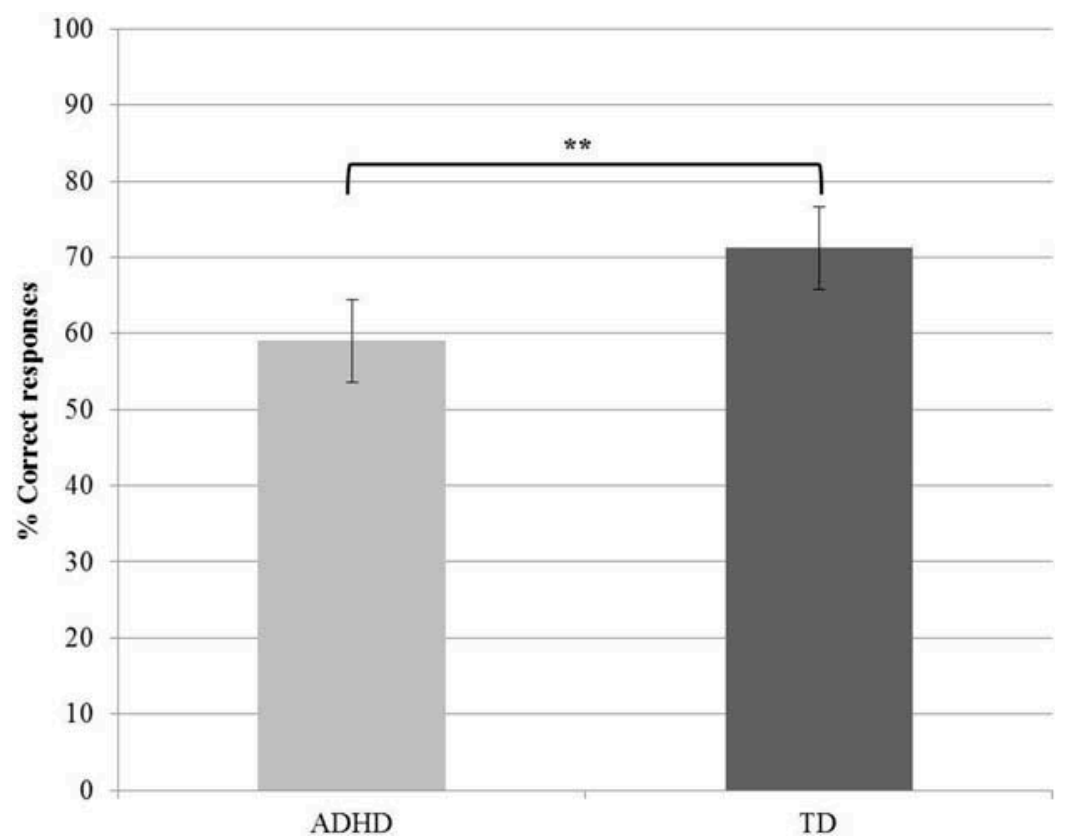

Figure 2 Reading the Mind in the Eyes task. Percentage of correct answers and error bars (95\% confidence interval) in typically developing (TD) and ADHD children $(* * p<.01)$. 
Table 2 Correlational Pearson's Coefficient for the ADHD Group.

\begin{tabular}{lll}
\hline & FPQ & \% Eyes task \\
\hline Mean tonic alertness (Median) & -.225 & -.308 \\
Mean tonic alertness (CV) & -.025 & $-.408^{*}$ \\
Divided attention (omissions) & $-.39^{*}$ & -.182 \\
Counting Stroop Task (Time interference index) & $-.571^{* *}$ & -.313 \\
Counting Stroop Task (Errors interference index) & -.261 & -.216 \\
Go/No-Go (Median) & .036 & -.242 \\
Tower of London (sum of exceeding movements) & -.043 & .107 \\
RCST (Total errors) & $-.414^{*}$ & -.179 \\
Flexibility (Median) & .048 & -.143 \\
Flexibility (Correct responses) & .32 & -.331 \\
\hline
\end{tabular}

Note. FPQ = mean "faux pas" detection and identification Questions, RCST = Revised Card Sorting Test.

$* p<.05 . * * p<.01$.

to the "faux pas" detection and identification questions (FPQ) and the percentage of correct answers in the Reading the Mind in the Eyes task were entered in the analysis.

Percentage of correct answers to FPQ in children with ADHD correlated significantly with the omissions in the divided attention subtest $(r=-.38 ; p=.036)$, the time interference index in the Counting Stroop task $(r=-.574 ; p=.001)$, and the errors in the $\operatorname{RCST}(r=-.396 ; p=.027)$. Also, performance in the Reading the Mind in the Eyes task correlated with the coefficient of variation in the TAP tonic alertness subtest $(r=-.408$; $p=.023$ ). Stepwise linear regressions were conducted in the ADHD group to determine which attentional and/or executive variable(s) best predicted a significant amount of variance in ToM testing. Regression analyses indicated that the time interference index in the Counting Stroop task best predicted the percentage of correct answers in the FPQ, $t(27)=-2.94, p=.007$. The coefficient of variation in the TAP alertness subtest was the only variable correlated to the Reading the Mind in the Eyes task; therefore, no regression analysis was computed.

Based on these associations, we conducted mediation analyses using a freely-available computational tool for mediation, moderation and conditional process analysis named PROCESS (Hayes, 2013). These analyses aimed at controlling how the performance in advanced ToM tasks is mediated by inhibitory and attentional components. For the "Faux Pas" task, a simple mediation model was computed with Group (ADHD vs. TD) as the independent variable, the percentage of correct responses in the "Faux Pas" Question (FPQ) as the dependent variable, and the Time Interference Index in the Counting Stroop task as the mediator variable. The relationship between Group and FPQ was mediated by Time Interference Index in the Counting Stroop task. As Figure 3A illustrates, the standardized regression coefficient between Group and the Time Interference Index was statistically significant, as was the standardized regression coefficient between the Time Interference Index and FPQ. The standardized indirect effect was $(-0.557)(-0.615)=0.343$. We tested the significance of this indirect effect using bootstrapping procedures. Unstandardized indirect effects were computed for each of the 10,000 bootstrapped samples, and the $95 \%$ confidence interval was computed by determining the indirect effects at the 2.5 th and 97.5 th percentiles. The bootstrapped unstandardized indirect effect was 16.496 , and the $95 \%$ confidence interval ranged from 8.278 to 27.602 . The indirect effect was statistically 

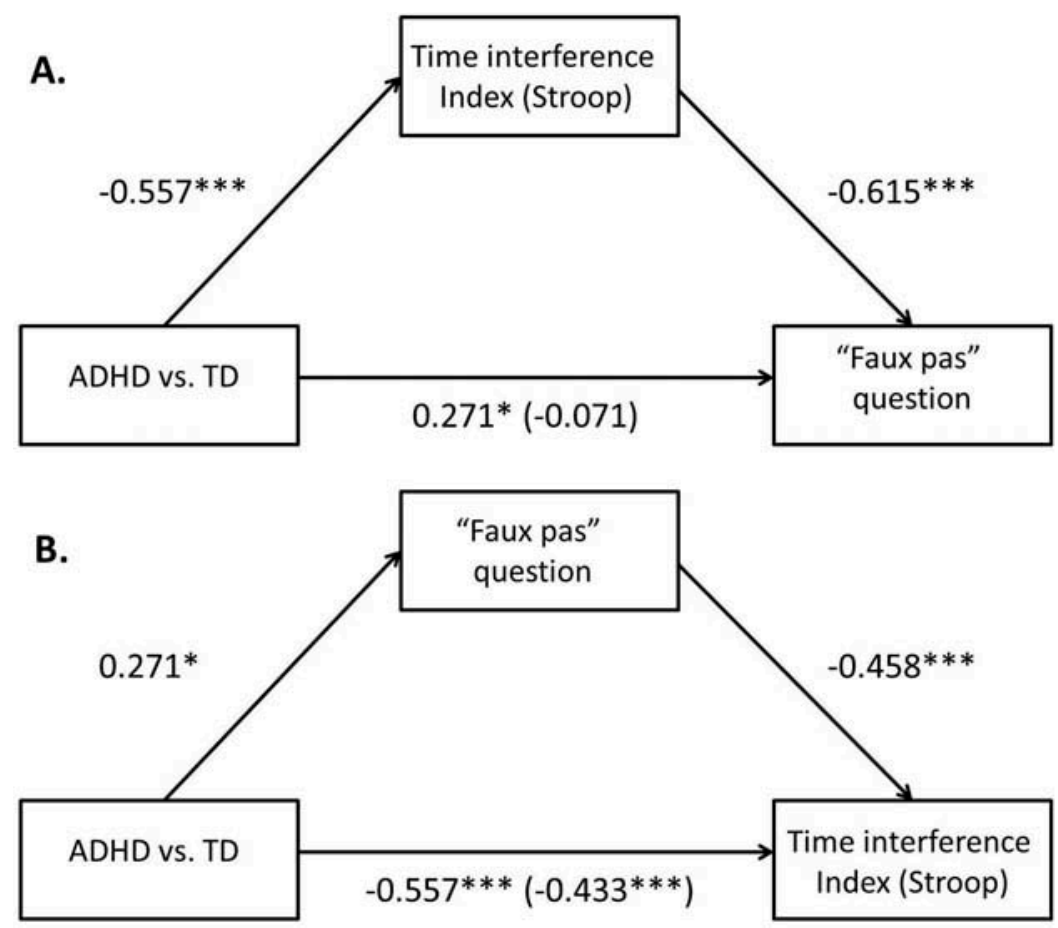

Figure 3 Mediation model for the relationship between the "Faux pas" and the Stroop tasks.

(A) Standardized regression coefficients for the relationship between Group (ADHD vs. TD) and "faux pas" question (FPQ) as mediated by Time Interference Index in the Counting Stroop. The standardized regression coefficient between Group and FPQ, controlling for time interference index, is in parentheses; (B) standardized regression coefficients for the relationship between Group (ADHD vs. TD) and Time Interference Index in the Counting Stroop as mediated by "faux pas" question (FPQ). The standardized regression coefficient between Group and time interference index, controlling for FPQ, is in parentheses $\left(* * * p<.001,{ }^{*} p<.05\right)$.

significant $(p<.001)$. The direct effect between Group and FPQ, controlling for the time interference index was not significant $(p=.580)$.

Because some authors have argued that ToM might be a prerequisite for EF development (Perner \& Lang, 1999), we also computed the reverse mediation model with FPQ as the mediator variable and the Time Interference Index in the Counting Stroop as the dependent variable. The relationship between Group and the Time Interference Index was not completely mediated by FPQ. As Figure 3B illustrates, the standardized regression coefficient between Group and FPQ was statistically significant, as was the standardized regression coefficient between FPQ and time interference. The standardized indirect effect was (0.271) $(-0.458)=-0.124$. The bootstrapped unstandardized indirect effect was -5.134 , and the $95 \%$ confidence interval ranged from -10.7268 to -0.840 . The indirect effect nearly reached statistical significance $(p=.051)$. The direct effect between Group and FPQ, controlling for the time interference index, was still significant $(p<.001)$.

For the Reading the Mind in the Eyes task, a simple mediation model was computed with Group (ADHD vs. TD) as the independent variable, the Percentage of Correct Responses in the Reading the Mind in the Eyes task as the dependent variable, and the 

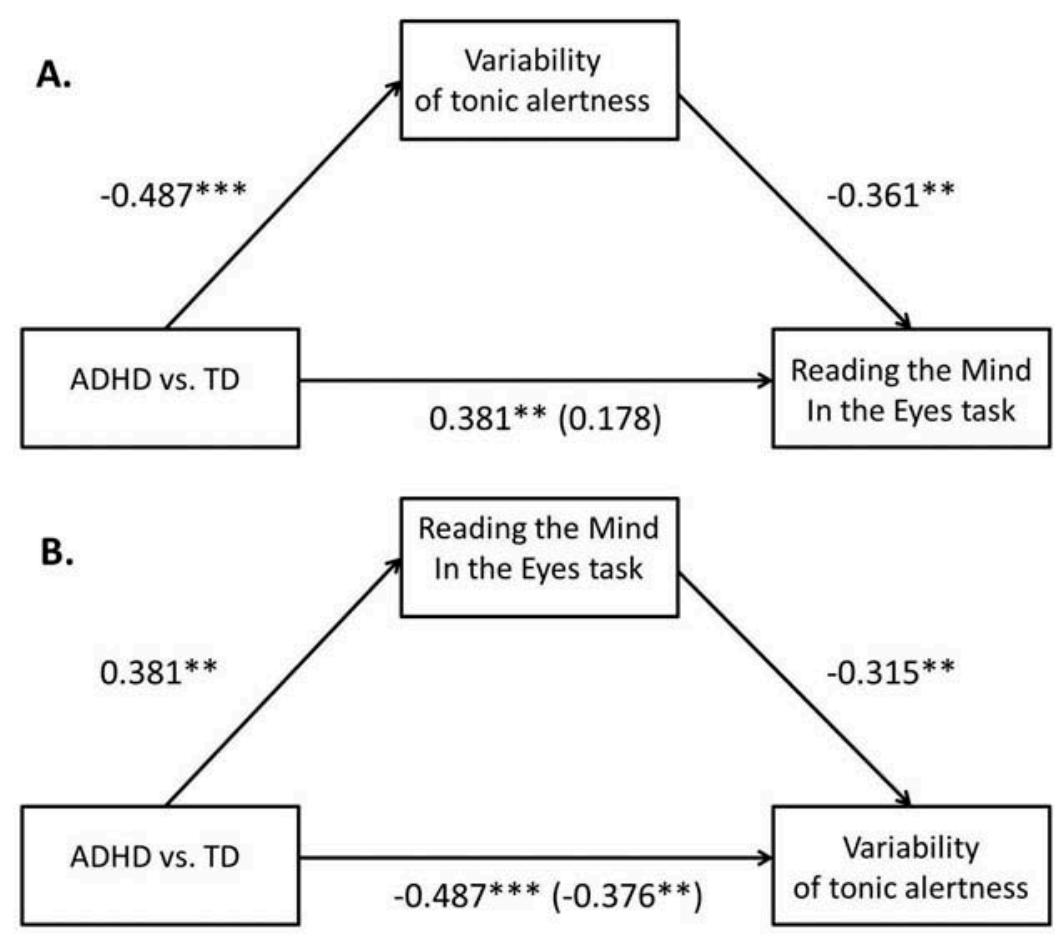

Figure 4 Mediation model for the relationship between the Reading the Mind in the Eyes task and the Alertness subtest.

(A) Standardized regression coefficients for the relationship between Group (ADHD vs. TD) and Reading the Mind in the Eyes as mediated by the Coefficient of Variation of tonic alertness. The standardized regression coefficient between Group and Reading the Mind in the Eyes, controlling for the coefficient of variation of tonic alertness, is in parentheses. (B) Standardized regression coefficients for the relationship between Group (ADHD vs. TD) and the Coefficient of Variation of tonic alertness as mediated by Reading the Mind in the Eyes. The standardized regression coefficient between Group and the Coefficient of Variation of tonic alertness, controlling for Reading the Mind in the Eyes, is in parentheses $(* * p<.01, * * * p<.001)$.

Coefficient of Variation in the TAP tonic alertness subtest as the mediator variable. The relationship between Group and Reading the Mind in the Eyes task was mediated by the Coefficient of Variation in tonic alertness. As Figure 4A illustrates, the standardized regression coefficient between Group and Coefficient of Variation in tonic alertness was statistically significant, as was the standardized regression coefficient between Coefficient of Variation in tonic alertness and Reading the Mind in the Eyes. The standardized indirect effect was $(-0.487)(-0.361)=0.176$. The bootstrapped unstandardized indirect effect was 5.658, and the $95 \%$ confidence interval ranged from 1.338 to 13.019 . The indirect effect was statistically significant $(p=.027)$. The direct effect between Group and Reading the Mind in the Eyes, controlling for the coefficient of variation in tonic alertness, was not significant $(p=.192)$.

We also computed the reverse mediation model with Reading the Mind in the Eyes as the mediator variable and the Coefficient of Variation in tonic alertness as the dependent variable. The relationship between Group and the Coefficient of Variation in 
tonic alertness was not completely mediated by Reading the Mind in the Eyes. As Figure 4B illustrates, the standardized regression coefficient between Group and Reading the Mind in the Eyes was statistically significant, as was the standardized regression coefficient between Reading the Mind in the Eyes and the Coefficient of Variation in tonic alertness. The standardized indirect effect was (0.381) $(-0.315)=-0.120$. The bootstrapped unstandardized indirect effect was -0.024 , and the $95 \%$ confidence interval ranged from -0.051 to -0.008 . The indirect effect was marginally significant $(p=.058)$. The direct effect between Group and the Coefficient of Variation in tonic alertness, controlling for Reading the Mind in the Eyes, was still significant $(p=.002)$.

\section{DISCUSSION}

Beyond the cognitive deficits, ADHD is also frequently associated with social dysfunction. The present study investigated ToM abilities in children with ADHD in order to determine if the executive and attentional impairments frequently identified in this population contribute to a potential ToM deficit. In the present study, we found that children with ADHD perform worse than typically developing children in executive tasks that assess inhibition (Counting Stroop task and Go/No-Go task), cognitive flexibility (RCST, TAP flexibility subtest), and planning (Tower of London), which is in line with studies showing deficits in the executive field (Pasini et al., 2007) and literature reviews (Sergeant et al., 2002; Willcutt et al., 2005) evidencing deficits in inhibition, flexibility, planning, and working memory in ADHD. Furthermore, our results show that children with ADHD also have slower latencies and higher intraindividual variability in the TAP tonic alertness subtest. This higher variability corroborates the description of a greater proportion of abnormally slower responses that have already been made in similar reports studying children with ADHD (Drechsler et al., 2005; Hervey et al., 2006; Leth-Steensen, King Elbaz, \& Douglas, 2000). The higher latencies observed in our sample might accordingly reflect more of a periodic distractibility during the course of a continuous task rather than a generalized slowdown for all responses (Hervey et al., 2006; LethSteensen et al., 2000; Tucha et al., 2006). Lapses of attention might also lead to an increased number of omissions as detected in the divided attention subtest (Tucha et al., 2006).

Regarding ToM functions, results from the Reading the Mind in the Eyes task show that children with ADHD perform more poorly than typically developing children. Using the Reading the Mind in the Eyes task, it has been shown that adolescents with ADHD present an intermediate performance between adolescents with ASD and control groups (Demurie, De Corel, \& Roeyers, 2011). In the "Faux Pas" task, we found that children with ADHD perform worse than the comparison group to the "faux pas" question but answer as accurately in questions involving other's beliefs. We expected a more obvious deficit in the advanced "Faux Pas" task since this task is reputedly more related to executive functions than the Reading the Mind in the Eyes task (Ahmed \& Miller, 2011; Kaland et al., 2002; Stone et al., 2003). By contrast, false belief questions used in the "Faux Pas" task correspond to first-order competencies developed early in childhood, around the age of 4-5 years (Sabbagh, Moses, \& Shiverick, 2006). The absence of a deficit for this task in children with ADHD is in accordance with previous findings (Buitelaar et al., 1999; Hughes et al., 1998; Papadopoulos et al., 2005; Yang et al., 2009). Here, children aged 8-12 years old had, more than likely, already developed 
these first-order competencies. Our data indicate that both the Reading the Mind in the Eyes and the "Faux Pas" tasks are altered in ADHD. Our results also suggest that the Reading the Mind in the Eyes task is not a "pure" ToM task devoid of attentional requirements since the direct effect of the Group factor (ADHD vs. typically developing children) on the Reading the Mind in the Eyes task is no longer significant when entering the attentional variable as a mediator.

In this respect, our analyses have yielded correlations between performances on ToM, executive and attentional tasks in children with ADHD, which is in agreement with previous studies (Charman et al., 2001; Fahie \& Symons, 2003; Henry, Phillips, Crawford, Ietswaart, \& Summers, 2006; Hughes et al., 1998; Perner et al., 2002; Sabbagh et al., 2006). Mediation analyses showed that when performance in the Reading the Mind in the Eyes task was controlled for attentional abilities and performance in the "Faux Pas" task was controlled for inhibition, the direct effects of ADHD on ToM abilities were no longer significant. Attentional disorders that feature ADHD seem to mediate performance deficits in the Reading the Mind in the Eyes task in this population. In this respect, impairment in the Reading the Mind in the Eyes task in ADHD might be due to an abnormal allocation of attention on the pictures of eyes. Finally, the mediation effect of inhibition on the "Faux Pas" task corroborates results suggesting deficits in advanced ToM tasks with higher demands on inhibition in children with ADHD (Sodian et al., 2003). Furthermore, when ToM performance was used as a mediator, the direct effects of the Group factor (ADHD vs. typically developing children) were still significant for both inhibition (Stroop) and vigilance (alertness). Thus, our findings suggest that ToM deficits in children with ADHD are mediated by the negative impact of attentional and executive dysfunctions on ToM tasks. These findings are in agreement with the hypothesis suggesting that social cognitive deficits in ADHD are partially due to inattention and inhibitory difficulties that stem from the core symptoms of the disorder, namely inattention and hyperactivity/impulsivity (Nijmeijer et al., 2008; Uekermann et al., 2010).

The present study may also give insights regarding the relationship between ADHD and Autism spectrum disorder (ASD). Recently, the comparison of these two disorders has attracted a growing interest (e.g., Gargaro, Rinehart, Bradshaw, Tonge, \& Sheppard, 2011). Notably, the latest version of the DSM (DSM-V; American Psychiatric Association, 2013) has included the potential comorbidity between both disorders. ADHD and ASD have both been associated with executive function problems and social difficulties (Bühler et al., 2011). ToM deficits in ASD are also largely documented (e.g., Baron-Cohen \& Belmonte, 2005). Recent findings demonstrate that autistic and ADHD traits may share some common genetic etiology (Rommelse, Franke, Geurts, Hartman, \& Buitelaar, 2010) that might explain social and executive problems in both disorders. However, a recent review suggested that deficits in EF might differ between ADHD and autism (Gargaro et al., 2011). In this respect, ADHD would be characterized by core inhibition and attentional deficits, while ASD would feature more deficits in flexibility and planning (e.g., Gargaro et al., 2011). In line with these observations, our results indicate that inhibition and attentional deficits contribute significantly to ToM deficits in ADHD. Therefore, ToM deficits in ASD should differ from those in ADHD and should be better explained by flexibility and planning than by inhibition or attentional performances. Direct comparisons of ToM abilities between ADHD, ASD, and typically developing children, controlling for mediators like EF and attentional processes, should be conducted to test this hypothesis. 
We believe that the use of a large variety of EF and attentional measures is an asset in the present study, as it offers a more comprehensive view of the cognitive domains that can be related to EF in ADHD. Also, unlike previous studies conducted in ADHD populations, we have tried to take into account the executive demands in ToM tasks by using two tasks, each of which having their own level of executive requirements, that is, the "Faux Pas" and the Reading the Mind in the Eyes tasks. Notwithstanding, limitations must also be considered in the interpretation of our results. First, the use of supplementary ToM tasks involving additional ToM abilities (e.g., second-order false beliefs tasks) might bring about complementary information concerning the involvement of $\mathrm{EF}$ and attentional deficits in the understanding of the socioemotional problems reported in ADHD. Second, learning disabilities (calculating, reading, and writing disorders) were not systematically screened in the present population. Although all the children attended normal school suggesting a reduced impact of possible learning difficulties, several studies have shown a high comorbidity rate of learning disabilities in children with ADHD (Eden \& Vaidya, 2008; Willcutt, Pennington, Olson, Chhabildas, \& Hulslander, 2005; Williamson, Murray, Damaraju, Ascher, \& Starr, 2012). Consequently, potential learning disorders may have accentuated executive difficulties (Willcutt et al., 2005), which might explain a part of the variance in the relationship between EF and ToM tasks. Third, even though our groups were matched on chronological age, they still differed on estimated IQ. However, IQ scores were not correlated with the "Faux Pas" $(r=.19, p=.31)$ nor the Reading the Mind in the Eyes $(r=.18, p=.33$ ) tasks in the ADHD group, suggesting that the variable did not strongly contribute to the observed findings. Lastly, it remains difficult to determine whether, and to what extent, children with ADHD exhibit inadequate social behaviors and experience problems in their daily social interactions. As ToM deficits are supposed to contribute to social and emotional malfunctioning in ADHD, new scales and questionnaires assessing both social and emotional abilities should be included in future research to determine whether, and to what extent, EF deficits in ADHD are related to their socioemotional difficulties. Hopefully, these investigations will aid in understanding whether children with both ADHD and socioemotional impairments in daily life have more EF deficits than children without socioemotional impairments.

To sum up, our results cannot corroborate studies that suggest a primary ToM deficit in ADHD (Buitelaar et al., 1999; Hughes et al., 1998; Papadopoulos et al., 2005). When executive and attentional functions are used as a mediator, no direct effects of the Group factor on ToM tasks remain significant, suggesting that known socioemotional difficulties in ADHD (Razza \& Blair, 2009) might, to a large extent, be due to their EF and attentional difficulties. However, all children with ADHD do not experience social dysfunction (Nijmeijer et al., 2008). Future research should therefore investigate the exact involvement of the symptoms, the cognitive deficits and their severity in the social dysfunction observed in ADHD. Another important issue concerns the small amount of studies focused on the effects of ADHD treatments on social function, despite the fact that social problems in children with ADHD may have long-term negative consequences. Future research should investigate the effect of stimulant medication (e.g., methylphenidate) on ToM abilities, since this treatment has proven to be efficient in reducing cognitive inattention and impulsivity symptoms in ADHD (Swanson, Baler, \& Volkow, 2011). Indeed, if EF and attention mediate ToM deficits in ADHD, medication-related improvement in executive and attentional tasks should secondarily improve performance on ToM tasks. Finally, children with ADHD do not seem to exhibit a ToM deficit at an early age. This deficit has been suggested to develop later in higher level ToM functions involving 
their executive or attentional weaknesses (e.g., Bühler et al., 2011; Sodian et al., 2003). EF deficits in ADHD appear to be stable over time and persist through young adulthood (Biederman et al., 2007). These findings in conjunction with the lack of studies concerning ToM in adults with ADHD highlight the need to assess both the evolution of ToM deficits in ADHD into adulthood, as well as how adults with ADHD deal with their social relationships. Moreover, the possible involvement of dysfunctional neuronal regions related to ADHD in the development of social cognition (Soliva et al., 2009) leaves issues concerning the developmental and neurocognitive aspects of ToM and EF in ADHD open.

Adequate interactions with others are essential for developing constructive social relationships. As a consequence of their inappropriate social behaviors, children with ADHD have been reported to have fewer friends and more difficulties maintaining friendships (Nijmeijer et al., 2008). Thus, social impairments may result in a "vicious circle" in which patients with ADHD experience less positive social interactions where they may develop a better interpretation and comprehension of others' feelings (Yuill \& Lyon, 2007). Our findings indicate that the inhibitory and attentional problems, as opposed to ToM deficits, may negatively impact the social functioning ability of children with ADHD. A better understanding of the mechanisms underlying the social difficulties associated with ADHD is crucial in facilitating the development of intervention programs designed to circumvent this impairment in the educational, behavioral, social, and affective domains. Most importantly, socioemotional difficulties may impair the prognosis of ADHD (Greene, Biederman, Faraone, Sienna, \& Garcia-Jetton, 1997), highlighting the importance of systematically assessing social cognition in the clinical practice and adapting treatment strategies in order to introduce adapted care when necessary.

Original manuscript received 30 August 2013 Revised manuscript accepted 22 January 2015 First published online 13 March 2015

\section{REFERENCES}

Aboulafia-Brakha, T., Christe, B., Martory, M.-D., \& Annoni, J.-M. (2011). Theory of mind tasks and executive functions: A systematic review of group studies in neurology. Journal of Neuropsychology, 5(1), 39-55. doi:10.1348/174866410X533660

Ahmed, F. S., \& Miller, L. S. (2011). Executive function mechanisms of theory of mind. Journal of Autism and Developmental Disorders, 41(5), 667-678. doi:10.1007/s10803-010-1087-7

Alloway, T. P. (2010). Working memory and executive function profiles of individuals with borderline intellectual functioning. Journal of Intellectual Disability Research, 54(5), 448-456. doi:10.1111/j.1365-2788.2010.01281.x

American Psychiatric Association. (2000). Diagnostic and statistical manual of mental disorders (4th ed.). Text Revision. Washington, DC: Author.

American Psychiatric Association. (2013). Diagnostic and statistical manual of mental disorders (5 ed.). DSM-5. Washington, DC: American Psychiatric Publishing.

Arffa, S. (2007). The relationship of intelligence to executive function and non-executive function measures in a sample of average, above average, and gifted youth. Archives of Clinical Neuropsychology, 22(8), 969-978. doi:10.1016/j.acn.2007.08.001

Barbey, A. K., Colom, R., Solomon, J., Krueger, F., Forbes, C., \& Grafman, J. (2012). An integrative architecture for general intelligence and executive function revealed by lesion mapping. Brain, 135(4), 1154-1164. doi:10.1093/brain/aws021 
Barkley, R. A. (1998). Attention - deficit hyperactivity disorder: A handbook for diagnosis and treatment. New York, NY: The Guilford Press.

Barkley, R. A., \& Murphy, K. R. (1998). Attention-deficit hyperactivity disorder: A clinical workbook (2nd ed.). New York, NY: Guilford Press.

Baron-Cohen, S., \& Belmonte, M. K. (2005). AUTISM: A window onto the development of the social and the analytic brain. Annual Review of Neuroscience, 28(1), 109-126. doi:10.1146/ annurev.neuro.27.070203.144137

Baron-Cohen, S., O’Riordan, M., Stone, V., Jones, R., \& Plaisted, K. (1999). Recognition of Faux Pas by normally developing children and children with Asperger syndrome or high-functioning Autism. Journal of Autism and Developmental Disorders, 29(5), 407-418. doi:10.1023/ A: 1023035012436

Baron-Cohen, S., Wheelwright, S., Spong, A., Scahill, V., \& Lawson, J. (2001). Are intuitive physics and intuitive psychology independent? A test with children with Asperger Syndrome. Journal of Developmental and Learning Disorders, 5, 47-78.

Biederman, J., Petty, C. R., Fried, R., Doyle, A. E., Spencer, T., Seidman, L. J., ... Faraone, S. V. (2007). Stability of executive function deficits into young adult years: A prospective longitudinal follow-up study of grown up males with ADHD. Acta Psychiatrica Scandinavica, 116(2), 129-136. doi:10.1111/j.1600-0447.2007.01008.x

Bühler, E., Bachmann, C., Goyert, H., Heinzel-Gutenbrunner, M., \& Kamp-Becker, I. (2011). Differential diagnosis of autism spectrum disorder and attention deficit hyperactivity disorder by means of inhibitory control and 'theory of mind'. Journal of Autism and Developmental Disorders, 41(12), 1718-1726. doi:10.1007/s10803-011-1205-1

Buitelaar, J. K., Van Der Wees, M., Swaab-Barneveld, H., \& Van Der Gaag, R. J. (1999). Theory of mind and emotion-recognition functioning in autistic spectrum disorders and in psychiatric control and normal children. Development and Psychopathology, 11(1), 39-58. doi:10.1017/ S0954579499001947

Bush, G., Frazier, J. A., Rauch, S. L., Seidman, L. J., Whalen, P. J., Jenike, M. A., ... Biederman, J. (1999). Anterior cingulate cortex dysfunction in attention-deficit/hyperactivity disorder revealed by fMRI and the counting stroop. Biological Psychiatry, 45(12), 1542-1552. doi:10.1016/S0006-3223(99)00083-9

Bush, G., Whalen, P. J., Rosen, B. R., Jenike, M. A., McInerney, S. C., \& Rauch, S. L. (1998). The counting stroop: An interference task specialized for functional neuroimaging validation study with functional MRI. Human Brain Mapping, 6(4), 270-282. doi:10.1002/(SICI)1097-0193 (1998)6:4<270::AID-HBM6>3.0.CO;2-0

Charman, T., Carroll, F., \& Sturge, C. (2001). Theory of mind, executive function and social competence in boys with ADHD. Emotional and Behavioural Difficulties, 6(1), 31-49. doi: $10.1080 / 13632750100507654$

Daly, B., Creed, T., Xanthopoulos, M., \& Brown, R. (2007). Psychosocial treatments for children with attention deficit/hyperactivity disorder. Neuropsychology Review, 17(1), 73-89. doi:10.1007/s11065-006-9018-2

Demurie, E., De Corel, M., \& Roeyers, H. (2011). Empathic accuracy in adolescents with autism spectrum disorders and adolescents with attention-deficit/hyperactivity disorder. Research in Autism Spectrum Disorders, 5(1), 126-134. doi:10.1016/j.rasd.2010.03.002

Diamond, A. (2013). Executive functions. Annual Review of Psychology, 64(1), 135-168. doi:10.1146/annurev-psych-113011-143750

Drechsler, R., Brandeis, D., Foldenyi, M., Imhof, K., \& Steinhausen, H.-C. (2005). The course of neuropsychological functions in children with attention deficit hyperactivity disorder from late childhood to early adolescence. Journal of Child Psychology and Psychiatry, 46(8), 824-836. doi:10.1111/j.1469-7610.2004.00384.x

Durston, S., de Zeeuw, P., \& Staal, W. G. (2009). Imaging genetics in ADHD: A focus on cognitive control. Neuroscience and Biobehavioral Reviews, 33(5), 674-689. doi:10.1016/j. neubiorev.2008.08.009 
Eden, G. F., \& Vaidya, C. J. (2008). ADHD and developmental dyslexia. Annals of the New York Academy of Sciences, 1145(1), 316-327. doi:10.1196/annals.1416.022

Fahie, C. M., \& Symons, D. K. (2003). Executive functioning and theory of mind in children clinically referred for attention and behavior problems. Journal of Applied Developmental Psychology, 24, 51-73. doi:10.1016/S0193-3973(03)00024-8

Friedman, N. P., Miyake, A., Corley, R. P., Young, S. E., DeFries, J. C., \& Hewitt, J. K. (2006). Not all executive functions are related to intelligence. Psychological Science, 17(2), 172-179. doi:10.1111/j.1467-9280.2006.01681.x

Gargaro, B. A., Rinehart, N. J., Bradshaw, J. L., Tonge, B. J., \& Sheppard, D. M. (2011). Autism and ADHD: How far have we come in the comorbidity debate? Neuroscience \& Biobehavioral Reviews, 35(5), 1081-1088. doi:10.1016/j.neubiorev.2010.11.002

Goyette, C. H., Conners, C. K., \& Ulrich, R. F. (1978). Normative data on revised Conners parent and teacher rating scales. Journal of Abnormal Child Psychology, 6(2), 221-236. doi:10.1007/ BF00919127

Greene, R. W., Biederman, J., Faraone, S. V., Sienna, M., \& Garcia-Jetton, J. (1997). Adolescent outcome of boys with attention-deficit/hyperactivity disorder and social disability: Results from a 4-year longitudinal follow-up study. Journal of Consulting and Clinical Psychology, 65(5), 758-767. doi:10.1037/0022-006X.65.5.758

Hayes, A. F. (2013). Introduction to mediation, moderation, and conditional process analysis: A regression-based approach. New York, NY: The Guilford Press.

Henry, J. D., Phillips, L. H., Crawford, J. R., Ietswaart, M., \& Summers, F. (2006). Theory of mind following traumatic brain injury: The role of emotion recognition and executive dysfunction. Neuropsychologia, 44(10), 1623-1628. doi:10.1016/j.neuropsychologia.2006.03.020

Hervey, A. S., Epstein, J. N., Curry, J. F., Tonev, S., Eugene Arnold, L., Keith Conners, C., ... Hechtman, L. (2006). Reaction time distribution analysis of neuropsychological performance in an ADHD sample. Child Neuropsychology, 12(2), 125-140. doi:10.1080/09297040500499081

Hughes, C., Dunn, J., \& White, A. (1998). Trick or treat?: Uneven understanding of mind and emotion and executive dysfunction in "hard-to-manage" preschoolers. Journal of Child Psychology and Psychiatry, 39(7), 981-994. doi:10.1111/1469-7610.00401

Kaland, N., Møller-Nielsen, A., Callesen, K., Mortensen, E. L., Gottlieb, D., \& Smith, L. (2002). A new 'advanced' test of theory of mind: Evidence from children and adolescents with Asperger syndrome. Journal of Child Psychology and Psychiatry, 43(4), 517-528. doi:10.1111/ 1469-7610.00042

Leth-Steensen, C., King Elbaz, Z., \& Douglas, V. I. (2000). Mean response times, variability, and skew in the responding of ADHD children: A response time distributional approach. Acta Psychologica, 104(2), 167-190. doi:10.1016/S0001-6918(00)00019-6

MacLeod, C. M. (1991). Half a century of research on the Stroop effect: An integrative review. Psychological Bulletin, 109(2), 163-203. doi:10.1037/0033-2909.109.2.163

Miyake, A., Friedman, N. P., Emerson, M. J., Witzki, A. H., \& Howerter, A. (2000). The unity and diversity of executive functions and their contributions to complex "frontal lobe" tasks: A latent variable analysis. Cognitive Psychology, 41, 49-100. doi:10.1006/cogp.1999.0734

Nelson, H. E. (1976). A modified card sorting test sensitive to frontal lobe defects. Cortex: A Journal Devoted to the Study of the Nervous System and Behavior, 12(4), 313-324. doi:10.1016/S0010-9452(76)80035-4

Nijmeijer, J. S., Minderaa, R. B., Buitelaar, J. K., Mulligan, A., Hartman, C. A., \& Hoekstra, P. J. (2008). Attention-deficit/hyperactivity disorder and social dysfunctioning. Clinical Psychology Review, 28(4), 692-708. doi:10.1016/j.cpr.2007.10.003

Papadopoulos, T., Panayiotou, G., Spanoudis, G., \& Natsopoulos, D. (2005). Evidence of poor planning in children with attention deficits. Journal of Abnormal Child Psychology, 33(5), 611-623. doi:10.1007/s10802-005-6741-8 
Pasini, A., Paloscia, C., Alessandrelli, R., Porfirio, M. C., \& Curatolo, P. (2007). Attention and executive functions profile in drug naive ADHD subtypes. Brain and Development, 29(7), 400-408. doi:10.1016/j.braindev.2006.11.010

Perner, J., Kain, W., \& Barchfeld, P. (2002). Executive control and higher-order theory of mind in children at risk of ADHD. Infant and Child Development, 11(2), 141-158. doi:10.1002/icd.302

Perner, J., \& Lang, B. (1999). Development of theory of mind and executive control. Trends in Cognitive Sciences, 3(9), 337-344. doi:10.1016/S1364-6613(99)01362-5

Posner, M. I. (2008). Measuring alertness. Annals of the New York Academy of Sciences, 1129, 193-199. doi:10.1196/annals.1417.011

Premack, D., \& Woodruff, G. (1978). Does the chimpanzee have a theory of mind? Behavioral and Brain Sciences, 1(4), 515-526. doi:10.1017/S0140525X00076512

Razza, R. A., \& Blair, C. (2009). Associations among false-belief understanding, executive function, and social competence: A longitudinal analysis. Journal of Applied Developmental Psychology, 30, 332-343. doi:10.1016/j.appdev.2008.12.020

Rommelse, N., Franke, B., Geurts, H., Hartman, C., \& Buitelaar, J. (2010). Shared heritability of attention-deficit/hyperactivity disorder and autism spectrum disorder. European Child \& Adolescent Psychiatry, 19(3), 281-295. doi:10.1007/s00787-010-0092-x

Sabbagh, M. A., Moses, L. J., \& Shiverick, S. (2006). Executive functioning and preschoolers' understanding of false beliefs, false photographs, and false signs. Child Development, 77(4), 1034-1049. doi:10.1111/j.1467-8624.2006.00917.x

Schweizer, K., Moosbrugger, H., \& Goldhammer, F. (2005). The structure of the relationship between attention and intelligence. Intelligence, 33(6), 589-611. doi:10.1016/j. intell.2005.07.001

Sergeant, J. A., Geurts, H., \& Oosterlaan, J. (2002). How specific is a deficit of executive functioning for Attention-Deficit/Hyperactivity Disorder? Behavioural Brain Research, 130, 3-28. doi:10.1016/S0166-4328(01)00430-2

Shallice, T. (1982). Specific impairments of planning. Philosophical Transactions of the Royal Society of London. B, Biological Sciences, 298(1089), 199-209. doi:10.1098/rstb.1982.0082

Slama, H., Mary, A., Mousty, P., Massat, I., \& Peigneux, P. (2011). Theory of mind and ADHD. ADHD in Practice, 3(4), 4-7.

Sodian, B., Hülsken, C., \& Thoermer, C. (2003). The self and action in theory of mind research. Consciousness and Cognition, 12, 777-782. doi:10.1016/S1053-8100(03)00082-5

Soliva, J. C., Carmona, S., Fauquet, J., Hoekzema, E., Bulbena, A., Hilferty, J., \& Vilarroya, O. (2009). Neurobiological substrates of social cognition impairment in Attention-Deficit Hyperactivity Disorder. Annals of the New York Academy of Sciences, 1167(1), 212-220. doi:10.1111/j.1749-6632.2009.04604.x

Stone, V. E., Baron-Cohen, S., Calder, A., Keane, J., \& Young, A. (2003). Acquired theory of mind impairments in individuals with bilateral amygdala lesions. Neuropsychologia, 41, 209-220. doi:10.1016/S0028-3932(02)00151-3

Swanson, J., Baler, R. D., \& Volkow, N. D. (2011). Understanding the effects of stimulant medications on cognition in individuals with Attention-Deficit Hyperactivity Disorder: A decade of progress. Neuropsychopharmacology, 36(1), 207-226. doi:10.1038/npp.2010.160

Tucha, O., Walitza, S., Mecklinger, L., Sontag, T.-A., Kübber, S., Linder, M., \& Lange, K. W. (2006). Attentional functioning in children with ADHD - predominantly hyperactive-impulsive type and children with ADHD - combined type. Journal of Neural Transmission, 113(12), 1943-1953. doi:10.1007/s00702-006-0496-4

Uekermann, J., Kraemer, M., Abdel-Hamid, M., Schimmelmann, B. G., Hebebrand, J., Daum, I., ... Kis, B. (2010). Social cognition in attention-deficit hyperactivity disorder (ADHD). Neuroscience \& Biobehavioral Reviews, 34(5), 734-743. doi:10.1016/j.neubiorev.2009.10.009 Wechsler, D. (2005). WISC IV: Manuel d'administration et de cotation (4 ${ }^{\mathrm{e}}$ éd.). Paris: Editions du Centre de Psychologie Appliquée. 
Willcutt, E. G., Doyle, A. E., Nigg, J. T., Faraone, S. V., \& Pennington, B. F. (2005). Validity of the executive function theory of Attention-Deficit/Hyperactivity Disorder: A meta-analytic review. Biological Psychiatry, 57(11), 1336-1346. doi:10.1016/j.biopsych.2005.02.006

Willcutt, E. G., Pennington, B. F., Olson, R. K., Chhabildas, N., \& Hulslander, J. (2005). Neuropsychological analyses of comorbidity between reading disability and attention deficit hyperactivity disorder: In search of the common deficit. Developmental Neuropsychology, 27(1), 35-78. doi:10.1207/s15326942dn2701_3

Williamson, D., Murray, D. W., Damaraju, C. V., Ascher, S., \& Starr, H. L. (2012). Methylphenidate in children with ADHD with or without learning disability. Journal of Attention Disorders, 18 (2), 95-104. doi:10.1177/1087054712443411

Yang, J., Zhou, S., Yao, S., Su, L., \& McWhinnie, C. (2009). The relationship between theory of mind and executive function in a sample of children from mainland China. Child Psychiatry \& Human Development, 40(2), 169-182. doi:10.1007/s10578-008-0119-4

Yuill, N., \& Lyon, J. (2007). Selective difficulty in recognising facial expressions of emotion in boys with ADHD. European Child \& Adolescent Psychiatry, 16(6), 398-404. doi:10.1007/s00787007-0612-5

Zimmermann, P., \& Fimm, B. (2004). Tests d'évaluation de l'attention (TEA, version 1.6) : Normes pour enfants et adolescents, Manuel supplémentaire. Herzogenrath: Psytest. 